\title{
PERSEPSI SISWA MADRASAH TSANAWIYAH TERHADAP PENDIDIKAN MULTIKULTURAL KEAGAMAAN DALAM PENANGGULANGAN RADIKALISME SECARA DINI
}

\author{
E. Bahruddin, Abdu Rahmat Rosyadi, Edy \\ Pascasarjana Pendidikan Islam Universitas Ibn Khaldun Bogor \\ Pascasarjana Pendidikan Islam Universitas Ibn Khaldun Bogor \\ Sekolah Tinggi Ilmu Tarbiyah Sirojul Falah Cibinong \\ ebahruddin@yahoo.com
}

Received: 17-07-2018, Accepted: 13-08-2018, Publish: 03-09-2018

\begin{abstract}
Research on perceptions of Madrasah Tsanawiyah students towards religious multicultural education in combating radicalism early is carried out through a qualitative-descriptive approach with a population of 285 students and samples that answer questionnaires as many as 168 respondents $158.95 \%$ of the population of 285 students / $i$ ). From the sample answer the question with an ideal value on a scale of 5 of 86, 74\%. This shows that students' perception of religious multicultural education is very positive. The results of processing data from 30 items of statements submitted to the respondent mostly answered positively with an EXCELLENT score (SB). The results of this study can be concluded that the perception of students of Madrasah Tsanawiyah considers tolerance needs to be built in the diversity of the Indonesian people who are religious, ethnic, and indigenous who can prevent the practice of radicalism early from the basic education institutions.
\end{abstract}

Keywords: Student Perception, Multicultural Education, Religion, Radicalism

\begin{abstract}
ABSTRAK
Penelitian tentang persepsi siswa Madrasah Tsanawiyah terhadap pendidikan multikultural keagamaan dalam penanggulangan radikalisme secara dini dilaksanakan melalui pendekatan kualitatif-deskriptif dengan populasi sebanyak 285 siswa dan sample yang menjawab angket sebanyak 168 responden $(58,95 \%$ dari populasi 285 siswa/i). Dari sample tersebut menjawab pertanyaan dengan nilai ideal pada skala 5 sebesar 86, $74 \%$. Hal ini menunjukan bahwa persepsi siswa terhadap pendidikan multikultural keagamaan sangat positif. Hasil pengolahan data dari 30 item pernyataan yang disampaikan kepada responden itu sebagian besar menjawab positif dengan skore SANGAT BAIK (SB). Hasil penelitian ini dapat disimpulkan bahwa persepsi siswa Madrasah Tsanawiyah memandang sikap toleransi perlu dibangun dalam keberagaman bangsa Indonesia yang beragama agama, suku, dan adat yang dapat mencegah praktik radikalisme secara dini sejak dari lembaga pendidikan dasar.
\end{abstract}

Keywords: Persepsi Siswa, Pendidikan Multikultural, Keagamaan, Radikalisme

\section{PENDAHULUAN}

Radikalisme di Indonesia dewasa ini semakin masif yang terjadi di $\begin{array}{lllr}\text { berbagai } & \text { wilayah } & \text { dan } & \text { lapisan } \\ \text { masyarakat } & \text { termasuk } & \text { pada lembaga }\end{array}$ pendidikan tinggi. Radikalisme dalam 
berbagai bentuknya mengakibatkan perpecahan antar anak bangsa itu berkaitan dengan sara (suku, agama, ras dan adat). Isu sara yang mencuat paling kuat yaitu masalah agama sebagai sumber konflik horizontal. Sebagai fakta mencuatnya tindakan radikalisme pada lembaga pendidikan disampaikan seorang Guru Besar Universitas Malikussaleh-Aceh, bahwa hasil survey Badan Nasional Penanggulangan Terorisme (BNPT) di 15 provinsi menyebutkan $39 \%$ mahasiswa terpengaruh oleh NIIS (Negara Islam di Irak dan Suriah) dan faham al-Qaeda sehingga berperilaku radikalis. Data tersebut diserahkan ke pihak Kementerian Riset, Teknologi dan Pendidikan Tinggi. ${ }^{1}$

Fenomena radikalisme seperti digambarkan tersebut sesungguhnya berawal dari tahap berfikir seseorang. Apa yang disebut sebagai radical in maind atau tahapan pemikiran dalam paham radikal itu dapat ditanggulangi secara dini melalui pembelajaran agama dan keagamaan di tingkat pendidikan dasar. Proses pembelajaran agama dan keagamaan ini diharapkan dapat memberi pemahaman radikalisasi secara dini. Walaupun pembelajaran PAI dalam prosesnya lebih cenderung pada

\footnotetext{
${ }^{1}$ Apridar. (2018). Kompas. Jakarta: Media Group, hlm. 7.
}

ranah kognitif-yang seharusnya diarahkan pada ranah afektif dalam membentuk karakter "rahamatan lil alamin" bagi peserta didik supaya pemikiran radikalisme itu tidak merambah ke arah radical in attitude atau radical in action.

Para pendidik yang mengampu mata pelajaran PAI harus lebih konstruktif dalam memberikan hasil yang lebih baik dibanding dengan hanya mengedepankan teori-teori yang tidak memiliki padanan dalam literatur keagamaan. Berkenaan dengan fenomena radikalisme yang menyentuh bidang agama dan keagamaan tersebut nampaknya perlu penelitian terhadap persepsi peserta didik tentang persepsi pendidikan multikultural keagamaan pada pendidikan dasar (SD/MI dan SMP/M.Ts) sebagai upaya penanggulangan radikalisme secara dini.

\section{TINJAUAN PUSTAKA}

Salah satu cara untuk menghadapi perilaku radikalaisme secara dini dapat dilakukan melalui pendidikan multikultural keagamaan pada lembaga pendidikan dasar. Pendidikan nasional hendaknya berakar pada sejarah bangsa dan dikembalikan pada cita-cita dan tujuan utama pendidikan itu sendiri. Tujuan pendidikan nasional untuk 
berkembangnya potensi peserta didik agar menjadi manusia yang beriman dan bertakwa kepada Tuhan Yang Maha Esa, berakhlak mulia, sehat, berilmu, cakap, kreatif, mandiri, dan menjadi warga negara yang demokratis serta bertanggung jawab. ${ }^{2}$

Berbagai pendapat secara teoritis tentang pendidikan multikultural keagamaan disampaikan oleh Sudrajat, ${ }^{3}$ baginya dalam konteks Indonesia multikulturalisme selalu dikaitkan dengan keberagaman etnis agama, bahasa, warna kulit, dan lain sebagainya. Secara historis pemerintahan Orde Baru di bawah kepemimpinan Soeharto menganjurkan monokulturalisme dan menganggap tabu multikulturalisme yang disebutnya dengan terminologi SARA (suku, agama, dan ras). Seiring dengan semangat reformasi yang berbarengan dengan proses otonomisasi dan desentralisasi kekuasaan terjadi peningkatan gejala "provinsialisme" yang identik dengan etnisitas. Oleh karenanya muncul semangat egosentrisme, etnosentrisme yang di kemudian hari menimbulkan permasalahan rumit. Tragedi

2 Undang-Undang Nomor 20 Tahun 2003 tentang Sistem Pendidikan Nasional, Bab II Pasal 3.

Sudrajat. (2014). "Revitalisasi Pendidikan Multikultural dalam Pembelajaran". Jurnal Pembangunan Pendidikan: Fondasi dan Aplikasi. 2 (1), hlm. 1-21. kemanusiaan pada era 2000-an di berbagai daerah seperti Poso, Ambon, Sambas, Madura, dan lain-lain merupakan fakta yang tidak terbantahkan bahwa semangat otonomisasi dan desentralisasi yang tidak dibarengi dengan kesadaran multikulturalisme menimbulkan permasalahan baru yang lebih rumit untuk dipecahkan.

Mubarok $^{4}$ menyatakan bahwa keragaman itu muncul karena keterbatasan panca indera, akal dan bahasa baginya keragama memiliki akar terdalam dalam diri bangsa, yakni keterbatasan sumber pengetahuan, panca indera, akal dan bahasa. Keterbatasan diri dalam interaksi sosialnya, melahirkan pengelompokan di masyarakat hingga menjadi identitas. Konstelasi antar identitas tidak hanya melahirkan kerjasama tetapi juga seringkali berbuntut kekerasan dan menelan korban. Diperlukan harmonisasi untuk memperkuat keragaman dan menghindari malapetaka. Harmonisasi keragaman harus datang dari dalam diri, bukan dari luar. Kesadaran tersebut adalah

${ }^{4}$ Mubarok. (2010). "Memahami Kembali Arti Keragaman: Dimensi Eksistensial, Sosial dan Institusional". Harmoni: Jurnal Multicultural \& Multireligius. IX (35), hlm. 2334. 
kesadaran eksistensial, yakni perbedaan dan keragaman yang tidak bisa ditolak.

Mubit $^{5}$ menyatakan bahwa pada dasarnya multikulturalisme yang terbentuk di Indonesia merupakan akibat dari kondisi sosio-kultural maupun geografis yang begitu beragam dan luas. Menurut kondisi geografis, Indonesia memiliki banyak pulau di mana setiap pulau tersebut dihuni oleh sekelompok manusia yang membentuk suatu masyarakat. Dari masyarakat tersebut terbentuklah sebuah kebudayaan mengenai masyarakat itu sendiri. Tentu saja hal ini berimbas pada keberadaan kebudayaan yang sangat banyak dan beraneka ragam.

Arifin, ${ }^{6}$ menyatakan dalam kehidupan dewasa ini keberadaan suatu bangsa tidak bisa dilepaskan dari ketergantungan dengan bangsa lain dalam kehidupan global berbagai unsur kebudayan lebih cepat tersaji, kejadian yang terdapat di belahan bumi lain dapat dengan mudah di akses dalam hal ini John Naisbit dan Alvin Tofler memberi gambaran bahwa dunia saat ini

\footnotetext{
${ }^{5}$ Mubit, Rizal. (2016). "Peran Agama Dalam Multikulturalisme Masyarakat Indonesia". Jurnal Episteme: Jurnal Pengembangan ilmu Keislaman IAIN Tulungagung. 11(1), hlm. 56-72.

Arifin. (2012). "Implementasi Pendidikan Multikultural Dalam Praksis Pendidikan di Indonesia". Jurnal Pembangunan Pendidikan: Fondasi dan Aplikasi. 1 (1), hlm. 78-91.
}

terasa semakin sempit. Dunia merupakan suatu kampung besar (global village). Di era globalisasi dewasa ini kita tidak dapat melepaskan diri dari kehidupan global. Gelombang demokrasi semakin terbuka yang dampaknya bukan saja membawa nilainilai positif dalam pengertian penghormatan terhadap hak-hak asasi manusia ( HAM ) dan eksistensi kelompok masyarakat, tetapi juga mengandung bahaya perpecahan suatu negara.

Suyatno $^{7}$, menjelaskan Indikasi kegagalan tersebut tidak terlepas dari peranan guru pendidikan agama dalam memberikan pemahaman keagamaan kepada peserta didik. Ada sinyalemen bahwa pemahaman keagamaan yang dibangun selama ini melalui pendidikan agama berangkat dari suatu pandangan yang memposisikan "agama" sebagai sebuah ajaran yang bersifat absulut, statis dan baku. Konsekwensinya pemahaman dan pandangan terhadap paham pluralisme dan multikulturalisme hanyalah sebatas pada tatanan wacana pemikiran kajian keislaman, bahkan lebih ekstrim, muncul kecenderungan memaknainya sebagai sebuah propaganda Barat dalam upaya

7 Suyatno. (2013). "Multikulturalisme Dalam Sistem Pendidikan Agama Islam: Problematika Pendidikan Agama Islam di Sekolah”. Jurnal Addin, 7 (1), hlm. 47-61. 
menyerang dan menghapus tradisitradisi Nabi dan Sahabat yang selama ini secara konsisten dilestarikan oleh kelompok Islam fundamentalis.

Mujiburrahman ${ }^{8}$ menjelaskan pendapat Robert N. Bellah, sosiolog agama dari Amerika Serikat, mengatakan bahwa melalui Nabi Muhammad Saw di Jazirah Arab, Islam telah menjadi peradaban multikultural yang amat besar, dahsyat dan mengagumkan hingga melampaui kebesaran negeri lahirnya Islam sendiri, yaitu Jazirah Arab. Pada konteks ini, toleransi dan sikap saling menghargai karena perbedaan agama, sebagaimana diungkap Wilfred Cantwell Smith, perlu terus dijaga dan dibudayakan.

Edy ${ }^{9}$ menyatakan bahwa: multikultural sebagai sebuah pandangan tentang kebaragaman budaya bisa diterima dan disambut baik oleh kalangan liberal yakni kelompok yang mengusung kebebasan. Kebebasan adalah milik setiap manusia, namun dilain pihka banyak orang yang menggunakan kebebasan itu untuk melakukan kesewenangan yang pastinga dapat merugikan orang lain.

\footnotetext{
8 Mujiburrahman. (2013). "Islam Multikultural: Hikmah, Tujuan, dan Keanekaragaman alam Islam". Jurnal Addin. 7 (1), hlm. 92-107.

${ }^{9}$ Edy. (2018). Pendidikan Multikultural dalam perspektif Pendidikan Islam. Bogor: UIKA PRESS, hlm. 92.
}

\section{METODE PENELITIAN}

Penelitian dengan pendekatan kualitatifdeskriptif yakni analisis data dan interpretasi atas objek kajian yang bersifat interpretasi tentang arti data terhadap persepsi sebagai penomena sosial. Sumber penelitian ini bedasarkan buku panduan model kurikulum pendidikan Agama Islam berbasis multikultiural di sekolah dasar yang diterbitkan oleh Kementerian Agama Direktorat Jenderal Pendidikan Islam Direktorat Pendidikan Agama Islam. Selanjutnya hasil penelitian ini akan dikembangkan menjadi model pendidikan multikultural yang dapat diterapkan pada jenjang pendidikan menengah dan perguruan tinggi.

Sumber data menggunakan library research, maka sangat diperlukan sumber-sumber informasi baik primer maupunn sekunder, berbagai sumber informasi ini dapat berupa buku-buku, diktat, makalah, paper, Koran dan sumbersumber lain yang terkait dan relevan dengan kajian dalam disertasi ini.

Fokus penelitian di Madrasah Tsanawiyah Nurul Ihsan, Cibinong-Bogor dengan Populasi penelitian seluruh siswa/i sebanyak 285 siswa terdiri dari kelas VII: 74 siswa, kelas VIII berjumlah 119, dan kelas IX berjumlah 92 siswa. Sample penelitian secara proporsional sebanyak 
167 responden melalui teknik random sampling.

Pengukuran penelitian menggunakan skala Likert untuk menentukan skor jawaban: 5 Sangat Setuju (SS); 4 Setuju (S); 3 Ragu-ragu (RG); 2 Tidak Setuju (TS); dan 1 Sangat Tidak Setuju (STS). Untuk menghitung skor dalam menentukan rating scale dan jumlah seluruh jawaban menggunakan rumus Skor Kriterium $=$ nilai skala $\mathrm{x}$ jumlah responden. Dalam penelitian ini skore ideal: 5 Sangat Baik (SB), 4 Baik (B), 3 Cukup Baik (CB), 2 Kurang Baik (KB), dan 1 Sangat Kurang Baik (SKB).

\section{HASIL DAN PEMBAHASAN}

Dimensi pendidikan Islam meliputi pendidikan untuk kebahagiaan hidup di dunia sampai keselamatan hidup di akhirat. Berdasarkan konsep itu pendidikan Islam sebagai teori untuk menjadi reference sistem pendidikan lainnya. Pendidikan Islam wajib diselenggarakan dan wajib diikuti secara individual maupun secara kolektif dengan tujuan untuk memperkuat keimanan dan ketaqwaan kepada Allah Subhanahuwata'ala serta membentuk akhlak al-karimah agar manusia sebagai khalifah tetap dalam fithrahnya. Penyelenggaraan pendidikan Islam secara makro dalam lingkup negara menjadi tanggung jawab pemerintah. Pemerintah wajib membuat kebijakan salah satunya dalam bentuk regulsi dan implementasikannya.

Pendidikan Islam menurut Rosyadi $^{10}$ selain menjadi tanggung jawab pemerintah juga menjadi tanggung jawab masyarakat sebagai bagian dari negara. Pelaksanaan pendidikan Islam secara mikro sesungguhnya menjadi tanggung jawab utama dan pertama dalam lingkup keluarga adalah orangtua. Siapa dan pihak mana pun yang melaksanakan pendidikan Islam dimaksudkan untuk mencapai tujuan pendidikan sebagaimana diamanahkan oleh Allah S.W.T. yaitu untuk mempertahankan dan meningkatkan fitrah keimanan yang telah dianugerahkan kepada manusia sejak dalam kandungan.

Pendidikan Islam di Indonesia pada tataran praktis telah mengalami perubahan yang sangat mendasar. Perubahan berkaitan dengan kelembagaan pendidikan yang diselenggarakan melalui pendidikan umum dan pendidikan agama. Hal ini dapat mempengaruhi terhadap orientasi dan aspek pendidikan secara keseluruhan terutama dalam menetapkan tujuan dan mendisain kurikulum pendidikan. Pendidikan Islam sebagai sistem

10 Rosyadi. (2017). Pendidikan Islam dalam Perspektif Kebijakan Pendidikan Nasional. Bogor: UIKA PRESS, hlm. 27. 
mempunyai subsistemnya sendiri dalam bentuk pendidikan agama Islam dan pendidikan keagamaan Islam yang diimplementasikan dalam PAI di lembaga pendidikan dasar, menengah dan perguruan tinggi.

PAI harus berperan dalam meredam pemikiran dan paham radikalisme pada peserta didik sejak awal sebelum berkembang ke arah yang negatif dalam bentuk radikalisme ke berbagai ranah kehidupan di masyarakat. Saat ini, dampak radikalisme ini masuk ke wilayah kebijakan politik pemerintahan sehingga pihak pemerintah membentuk suatu badan yang bekerja untuk memasyarakatkan ideologi negara Pancasila supaya menjadi pijakan dalam bermasyarakat dan bernegara. Dengan ideologi yang sudah disepakati bersama oleh komponen bangsa itu diharapkan menjadi perekat yang memperkuat persatuan bangsa dan kesatuan masyarakat Indonesia.

Utusan kepresidenan yang bergerak dibidang kerukunan umat beragama menyelenggarakan kegiatan dengan tajuk Musyawarah Besar (MUBES) Pemuka Agama untuk Kerukunan Bangsa. Syamsuddin ${ }^{11}$ untuk dialog dan kerjasama antaragama dan peradaban menyatakan bahwa ada

${ }^{11}$ Syamsuddin. (2017). Republika. Jakarta, hlm. 12. tujuh isu kebangsaan yang dibahas dalam Muber yaitu: (1) pandangan dan sikap umat beragama tentang NKRI berdasarkan Pancasila; (2) pandangan dan sikap umat beragama tentang Bhinneka Tunggal Ika; (3) pandangan dan sikap umat beragama terhadap pemerintahan yang sah hasil pemilu demokratis berdasarkan konstitusi; (4) prinsip-prinsip kerukunan antarumat beragama; (5) etika kerukunan intragama; (6) penyiaran agama dan pendirina rumah ibadah; dan (7) rekomendasi tentang faktor-faktor nonagama yang mengganggu kerukunan antarumat beragama.

Pendidikan multikultural keagamaan memiliki masalah besar terutama di Indonesia, karena dalam pelaksanannya diperlukan pemikiran mendalam dan implementasinya memerlukam sumberdaya yang baik. Dalam konteks pendidikan di Indonesia, sebenarnya pendidikan multikultur sudah diajarkan dan dikembangkan dengan tidak menyebut multikultural secara langsung dan menggunakan istilah yang lain. Hakekat pendidikan sebenarnya terletak pada isi dan capaian, tidak hanya teoretis yang hampa nilai.

Walaupun sikap multikulturalisme sudah dipraktikkan sejak lama oleh para pendiri bangsa Indonesia, namun istilah multikultural menguat manakala terdapat pertentangan dan pertikaian 
suku bangsa yang ada di Indonesia ini.

Seiring perkembangan zaman dan

kebijakan yang berubah, pertentangan bernuansa SARA senantiasa terjadi walaupun motif dan penyebabnya bisa beragam. Gagasan Kementerian Agama melalui Direktorat Jenderal Pendidikan Islam Direktorat Pendidikan Agama Islam pada sekolah membuat Panduan Model Kurikulum Pendidikan Agama Islam Berbasis Multikultural sebagai bagian dari Pendidikan Agama Islam (PAI) pada pendidikan dasar.

Hasil penelitian tentang persepsi siswa Madrasah Tsanawiyah terhadap pendidikan multikultural keagamaan dalam penanggulangan radikalisme secara dini dengan populasi dan sample seperti dijelaskan pada bagian metode penelitian menunjukkan skor nilai sangat ideal. Dari sample yang diberi angket sebanyak 168 responden (58, 95\% dari populasi $285 \mathrm{siswa} / \mathrm{i})$ tersebut menjawab pertanyaan berada pada nilai ideal yaitu skala $5(86,74 \%)$. Hal ini menunjukan bahwa persepsi siswa terhadap pendidikan multikultural keagamaan sangat positif. Pengolahan data dari 27 item pernyataan yang disampaikan kepada responden itu sebagian besar menjawab positif dengan skore Sangat Baik/SB. Sedangkan yang menjawab pertanyaan dengan skor Baik/B hanya pada item 23 dan 28. Rekapitulasi data hasil angket dari 167 responden seperti terlihat pada tabel di bawah ini.

Tabel: Nilai-Nilai Pendidikan Multikultural Keagamaan

\begin{tabular}{|l|l|c|c|c|c|c|c|}
\hline NO. & $\begin{array}{c}\text { NILAI-NILAI } \\
\text { PENDIDIKAN } \\
\text { MULTIKULTURAL }\end{array}$ & SS & S & RG & TS & STS & SCORE \\
\hline$(1)$ & $(2)$ & $(3)$ & $(4)$ & $(5)$ & $(6)$ & $(7)$ & $(7)$ \\
\hline $1 . \quad$ & $\begin{array}{l}\text { Perbedaan agama, } \\
\text { suku, bahasa, warna } \\
\text { kulit, budaya dan } \\
\text { agama merupakan } \\
\text { karunia Allah } \\
\text { S.W.T., karena itu } \\
\text { setiap orang harus } \\
\text { menghargai } \\
\text { perbedaan tersebut. }\end{array}$ & 140 & 25 & 0 & 0 & 0 & 806 (SB) \\
\hline $\begin{array}{l}\text { Setiap orang } \\
\text { memiliki keragaman } \\
\text { (suku, bahasa, warna } \\
\text { kulit, budaya dan } \\
\text { agama) dari }\end{array}$ & 79 & 75 & 10 & 3 & 0 & 731 (SB) \\
\hline
\end{tabular}




\begin{tabular}{|c|c|c|c|c|c|c|c|}
\hline & $\begin{array}{l}\text { keragaman tersebut } \\
\text { sering memunculkan } \\
\text { argumen atau } \\
\text { pendapat yang } \\
\text { berbeda namun saya } \\
\text { tetap menghormati } \\
\text { dan bersikap positif } \\
\text { terhadap perbedaan } \\
\text { pendapat yang ada. }\end{array}$ & & & & & & \\
\hline 3. & $\begin{array}{l}\text { Saya memperhatikan } \\
\text { dengan sungguh- } \\
\text { sungguh ketika orang } \\
\text { lain yang memiliki } \\
\text { latar belakang berbeda } \\
\text { (suku, bahasa, warna } \\
\text { kulit, budaya dan } \\
\text { agama) ketika } \\
\text { mengemukakan } \\
\text { gagasan dan pendapat. }\end{array}$ & 52 & 75 & 31 & 7 & 2 & $669(\mathrm{SB})$ \\
\hline 4. & $\begin{array}{l}\text { Walaupun berlatar } \\
\text { belakang berbeda } \\
\text { (suku agama ras dan } \\
\text { Bahasa) saya } \\
\text { berupaya untuk } \\
\text { sumbang saran } \\
\text { dalam setiap } \\
\text { musyawarah. }\end{array}$ & 59 & 81 & 17 & 7 & 3 & $687(\mathrm{SB})$ \\
\hline 5. & $\begin{array}{l}\text { Dalam bergaul } \\
\text { dengan teman yang } \\
\text { berbeda latar } \\
\text { belakang agama, saya } \\
\text { sanggup memberi } \\
\text { bantuan material/non } \\
\text { material dalam } \\
\text { kegiatan yang positif. }\end{array}$ & 87 & 68 & 13 & 3 & 1 & $733(\mathrm{SB})$ \\
\hline 6. & $\begin{array}{l}\text { Keragaman budaya } \\
\text { dan suku bangsa tidak } \\
\text { menghalangi saya } \\
\text { untuk berpartisipasi } \\
\text { dalam kegiatan } \\
\text { kemasyarakatan. }\end{array}$ & 90 & 63 & 10 & 2 & 1 & $737(\mathrm{SB})$ \\
\hline 7. & $\begin{array}{l}\text { Walaupun berlatar } \\
\text { belakang berbeda, } \\
\text { namun saya mampu } \\
\text { memperlihatkan } \\
\text { sikap terbaik dan } \\
\text { menghindarkan diri } \\
\text { dari bersikap khianat } \\
\text { dalam pergaulan } \\
\text { hidup sehari-hari. }\end{array}$ & 106 & 48 & 10 & 2 & 1 & $757(\mathrm{SB})$ \\
\hline
\end{tabular}




\begin{tabular}{|c|c|c|c|c|c|c|c|}
\hline 8. & $\begin{array}{l}\text { Walaupun saya } \\
\text { dengan teman berbeda } \\
\text { latar belakang suku } \\
\text { agama dan ras, namu } \\
\text { saya tidak } \\
\text { merendahkannya baik } \\
\text { secara pribadi maupun } \\
\text { di tempat umum. }\end{array}$ & 122 & 43 & 2 & 0 & 0 & 788 (SB) \\
\hline 9. & $\begin{array}{l}\text { Dalam pergaulan yang } \\
\text { berbeda agama, } \\
\text { bahasa dan budaya, } \\
\text { saya mampu } \\
\text { meghargai dan } \\
\text { menjaga perasan } \\
\text { orang lain. }\end{array}$ & 91 & 68 & 8 & 0 & 0 & $751(\mathrm{SB})$ \\
\hline 10. & $\begin{array}{l}\text { Dalam pergaulan } \\
\text { yang berbeda agama, } \\
\text { bahasa dan budaya } \\
\text { saya tidak akan } \\
\text { menyinggung } \\
\text { perasaan orang lain, } \\
\text { baik sengaja maupun } \\
\text { tidak disengaja. }\end{array}$ & 76 & 83 & 5 & 3 & 0 & $733(\mathrm{SB})$ \\
\hline 11. & $\begin{array}{l}\text { Walaupun saya hidup } \\
\text { dalam lingkungan } \\
\text { yang beragam dan } \\
\text { berbeda, saya mampu } \\
\text { mengendalikan diri } \\
\text { dengan tidak menyin } \\
\text { ggung perasaan orang } \\
\text { lain atau teman saya } \\
\text { dalam kehidupan } \\
\text { sehari-hari. }\end{array}$ & 70 & 88 & 8 & 0 & 1 & 727 (SB) \\
\hline 12. & $\begin{array}{l}\text { Dalam keragaman } \\
\text { budaya, saya tidak } \\
\text { akan merendahkan } \\
\text { orang lain baik } \\
\text { sengaja ataupun } \\
\text { tidak senganja. }\end{array}$ & 75 & 77 & 14 & 1 & 0 & $726(\mathrm{SB})$ \\
\hline 13. & $\begin{array}{l}\text { Agama merupakan } \\
\text { sistem kepercayaan } \\
\text { yang diberikan } \\
\text { Tuhan, karena itu } \\
\text { saya selalu } \\
\text { Menghormati } \\
\text { keyakinan/ agama } \\
\text { yang dianut oleh } \\
\text { orang lain. }\end{array}$ & 70 & 77 & 12 & 4 & 4 & $706(\mathrm{SB})$ \\
\hline 14. & $\begin{array}{l}\text { Agama Islam } \\
\text { mengajarkan agar }\end{array}$ & 113 & 46 & 5 & 2 & 1 & 769 (SB) \\
\hline
\end{tabular}




\begin{tabular}{|c|c|c|c|c|c|c|c|}
\hline & $\begin{array}{l}\text { umatnya tidak } \\
\text { mengganggu ibadah } \\
\text { penganut agama lain. }\end{array}$ & & & & & & \\
\hline 15. & $\begin{array}{l}\text { Agama Islam } \\
\text { mengajarkan agar } \\
\text { umatnya Tidak } \\
\text { memaksakan } \\
\text { keyakinan/agama } \\
\text { kepada orang lain } \\
\text { yang berbeda. }\end{array}$ & 92 & 62 & 9 & 2 & 2 & 741 (SB) \\
\hline 16. & $\begin{array}{l}\text { Saya suka menolong, } \\
\text { mengayomi dan } \\
\text { mengasuh orang } \\
\text { yang lebih muda, } \\
\text { walaupun berbeda } \\
\text { latar belakang agama } \\
\text { dan keyakinan. }\end{array}$ & 46 & 101 & 17 & 3 & 0 & 691 (SB) \\
\hline 17. & $\begin{array}{l}\text { Menyayangi orang } \\
\text { lain seperti } \\
\text { menyayangi diri } \\
\text { sendiri. Walaupun } \\
\text { berbeda latar } \\
\text { belakang agama dan } \\
\text { keyakinan. }\end{array}$ & 76 & 72 & 14 & 2 & 3 & 717 (SB) \\
\hline 18. & $\begin{array}{l}\text { Walaupun berbeda } \\
\text { latar belakang agama } \\
\text { dan keyakinan saya } \\
\text { tidak akan benci dan } \\
\text { iri hati dalam } \\
\text { pergaulan sehari- } \\
\text { hari. }\end{array}$ & 65 & 94 & 7 & 1 & 0 & 724 (SB) \\
\hline 19. & $\begin{array}{l}\text { Memberikan bantuan } \\
\text { kepada setiap orang } \\
\text { yang membutuhkan } \\
\text { hendaklah tidak } \\
\text { melihat perbedaan } \\
\text { dan latar belakang } \\
\text { suku Agama ras dan } \\
\text { keyakinan. }\end{array}$ & 104 & 60 & 2 & 1 & 0 & 767 (SB) \\
\hline 20. & $\begin{array}{l}\text { Dalam kehidupan } \\
\text { masyarakat yang } \\
\text { beragam saya selalu } \\
\text { menghindarkan diri } \\
\text { dari sifat kikir dan } \\
\text { bakhil. }\end{array}$ & 96 & 63 & 6 & 2 & 0 & 752 (SB) \\
\hline 21. & $\begin{array}{l}\text { Saya sanggup } \\
\text { berbagi dengan } \\
\text { sesama (walaupun } \\
\text { berbeda keyakinan } \\
\text { dan agama) di kala }\end{array}$ & 83 & 69 & 10 & 4 & 1 & $730(\mathrm{SB})$ \\
\hline
\end{tabular}




\begin{tabular}{|c|c|c|c|c|c|c|c|}
\hline & $\begin{array}{l}\text { suka maupun duka } \\
\text { tanpa melihat } \\
\text { perbedaan latar } \\
\text { belakang budaya dan } \\
\text { agama. }\end{array}$ & & & & & & \\
\hline 22. & $\begin{array}{l}\text { Saya bersikap ikhlas } \\
\text { atas kehendak diri } \\
\text { sendiri kepada } \\
\text { siapapun tanpa } \\
\text { melihat latar belakang } \\
\text { Agama, suku bangsa } \\
\text { dan budaya. }\end{array}$ & 82 & 67 & 17 & 1 & 0 & 731 (SB) \\
\hline 23. & $\begin{array}{l}\text { Mendahulukan } \\
\text { kepentingan orang } \\
\text { lain didasarkan atas } \\
\text { prioritas keperluan } \\
\text { tanpa memperhatikan } \\
\text { perbedaan latar } \\
\text { belakang agama dan } \\
\text { budaya. }\end{array}$ & 46 & 77 & 27 & 11 & 6 & 647 (B) \\
\hline 24. & $\begin{array}{l}\text { Saya memberikan } \\
\text { perhatian kepada } \\
\text { kepentingan umum, } \\
\text { tanpa memperhatikan } \\
\text { perbedaan latar } \\
\text { belakang agama dan } \\
\text { budaya. }\end{array}$ & 65 & 62 & 32 & 7 & 1 & $684(\mathrm{SB})$ \\
\hline 25. & $\begin{array}{l}\text { Saya siap berkorban } \\
\text { untuk bangsa dan } \\
\text { Negara Tanpa } \\
\text { pamrih dan tidak } \\
\text { memeperhatikan } \\
\text { perbedaan latar } \\
\text { belakang agama dan } \\
\text { budaya. }\end{array}$ & 102 & 54 & 8 & 2 & 1 & $755(\mathrm{SB})$ \\
\hline 26. & $\begin{array}{l}\text { Saya mampu } \\
\text { menghindari sikap } \\
\text { egois, apatis dan } \\
\text { masa bodoh tanpa } \\
\text { memeperhatikan } \\
\text { perbedaan latar } \\
\text { belakang agama dan } \\
\text { budaya. }\end{array}$ & 55 & 74 & 27 & 6 & 5 & $669(\mathrm{SB})$ \\
\hline 27. & $\begin{array}{l}\text { Saya merasa berduka } \\
\text { atas musibah yang } \\
\text { menimpa orang lain. } \\
\text { Walaupun berlatar } \\
\text { belakang agama dan } \\
\text { budaya yang } \\
\text { berbeda. }\end{array}$ & 74 & 82 & 9 & 1 & 1 & $728(\mathrm{SB})$ \\
\hline
\end{tabular}




\begin{tabular}{|c|c|c|c|c|c|c|c|}
\hline 28. & $\begin{array}{l}\text { Saya mampu } \\
\text { merasakan kesulitan } \\
\text { dan penderitaan yang } \\
\text { dialami orang lain. } \\
\text { Tanpa melihat } \\
\text { perbedaan latar } \\
\text { belakang agama dan } \\
\text { budaya yang } \\
\text { berbeda. }\end{array}$ & 52 & 72 & 37 & 3 & 3 & 668 (B) \\
\hline 29. & $\begin{array}{l}\text { Saya tidak bersikap } \\
\text { masa bodoh terhadap } \\
\text { musibah yang } \\
\text { menimpa teman } \\
\text { maupun orang lain,. } \\
\text { Tanpa melihat } \\
\text { perbedaan latar } \\
\text { belakang agama dan } \\
\text { budaya yang } \\
\text { berbeda. }\end{array}$ & 54 & 92 & 13 & 5 & 3 & $690(\mathrm{SB})$ \\
\hline 30. & $\begin{array}{l}\text { Saya Ikut merasa } \\
\text { suka dan duka, jika } \\
\text { tema suka dan duka, } \\
\text { Tanpa melihat } \\
\text { perbedaan latar } \\
\text { belakang agama dan } \\
\text { budaya yang } \\
\text { berbeda. }\end{array}$ & 81 & 61 & 18 & 4 & 3 & $714(\mathrm{SB})$ \\
\hline
\end{tabular}

\section{Keterangan:}

1. Rating Scale Jawaban 669-835 (Sangat Baik/SB)

2. Rating Scale Jawaban 502-668 (Baik/B)

3. Rating Scale Jawaban 335-501 (Cukup Baik/CB)

4. Rating Scale Jawaban 168-334 (Kurang Baik/KB)

5. Rating Scale Jawaban 000-167 (Sangat Kurang Baik/SKB)

\section{Berdasarkan hasil penelitian} dengan metode survey melalui angket yang disampaikan kepada siswa Madrasah Tsanawiyah untuk mengetahui persepsi siswa terhadap pendidikan multikultural keagamaan hasilnya sangat positif. Persepsi positif inilah yang harus diperlihatkan siswa atas pemahaman pendidikan multikultura. Para siswa harus disadarkan oleh para pendidik bahwa keragaman bangsa Indonesia dalam berbagai adat, suku, dan agama harus menjadi rahmat bagi semua. Kebaragaman ini merupakan rahmat Allah atas bangsa Indonesia yang perlu disyukuri seperti disampaikan oleh Suparta $^{12}$ (2008: VIII) yang mengatakan

${ }^{12}$ Suparta. (2008). Islamic Multicultural Education. Sebuah Refleksi atas Pendidikan agama Islam di Indonesia. Jakarta: al-Ghazali Center, hlm. VIII. 
bahwa sekolah sebagai lembaga pendidikan merupakan miniatur dari perwujudan negara Indonesia yang majemuk. Sebagai miniatur, sekolah hendaknya sedini mungkin mengembangkan nilai-nilai yang sejalan dengan budaya bangsa yang telah dibangun oleh pendiri bangsa. Miniatur ini harus dikembangkan secara baik dan benar sehingga dari miniatur tersebut diharapkan bermunculan manusiamanusia berkualitas yang mampu mengembangkan sikap keberagaman dan keanekaragaman secara baik.

Persepsi positif tentang pendidikan multikultural disampaikan juga oleh Suryana $^{13}$ yang memaparkan tentang manusia dan pendidikan. Pendidikan sebagai proses transformasi budaya, pluralisme dan multikulturaisme, kultur bangsa yang damai dan toleran, politik identitas. Kerangka dasar pendidikan multikultural, strategi dan implementasi pendidikan multikultural dalam praktik pendidikan di Indonesia harus diupayakan oleh para pendidik. Penerapan pendidikan multikultural pada tingkat satuan pendidikan, model pembelajaran multikultural, model pengembangan kurikulum berbasis multikulural, dan model pengembangan

13 Suryana. (2015). Pendidikan Multikultural: Suatu Upaya Penguatan Jati Diri Bangsa. Bandung: Pustaka Setia, hlm. 24. materi pendidikan Agama Islam (PAI) mesti dilakukan dalam perspektif multikultural.

Dengan demikian menurut Nata ${ }^{14}$ pendidikan multikulturalisme sebagai tantangan-tantangan global masa depan dalam transformasi pendidikan nasional. Nata menejelaskan tentang kehidupan masa kini dan mendatang yang penuh tantangan sebagai ciri masyarakat global yakni pertama, kecenderungan untuk berinteraksi dalam kehidupan ekonomi dan kecenderungan untuk berpecah belah, kedua, Globalisasi, Ketiga, kemajuan sains dan tekhnologi yang akan mengubah secara radikal situasi dalam pasar tenaga kerja, keempat, industrialisasi dengan tekhnologi tinggi yang dapat mengubah cara orang mendapatkan nafkah. Kelima, pengaruh globalisasi akan menimbulkan gaya hidup yang berbeda dari tahun-tahun sebelumnya. Selanjutnya disebutkan bahwa pendidikan multikultural merupakan sebuah pendekatan progresif untuk melakukan transformasi pendidikan yang secara menyeluruh membongkar kekurangan, kegagalan dan parktikpraktik diskriminatif dalam proses pendidikan.

${ }^{14}$ Nata. (2005). Pendidikan Islam di Era Global: Pendidikan Mujltikultural, Pendidikan Multi Iman, Pendidikan Agama, Moral dan Etika. Jakarta: UIN Jakarta Press, hlm. 247-297. 
Apabila hasil penelitian terhadap persepsi siswa Tsanawiyah ini hasilnya menunjukkan negatif maka dianggap sebuah kegagalan para pendidik dalam menanamkan pendidikan multikultural di dalam lembaga pendidikan sehingga dianggap kehilangan arah. Anggapan ini disampaikan oleh Tilaar $^{15}$ bahwa pendidikan multikultur lebih menekankan bahwa pendidikan di Indonesia pada saat ini sudah kehilangan arah karenanya harus dikembalikan pada nilai-nilai budaya bangsa. Baginya multikulturalisme sudah berkembang di Indonesia dalam praktiknya pada masa lalu, masa kini dan masa Depan. Bagi Tilaar pendidikan multikultural merupakan pondasi yang perlu ditegaskan dalam upaya mewujudkan nasionalisme Indonesia Baru.

\section{Simpulan}

Berdasarkan analisis data hasil penelitian tentang persepsi siswa Madrasah Tsanawiyah terhadap pendidikan multikultural keagamaan dalam penanggulangan radikalisme secara dini ini didasarkan atas berbagai teori pendidikan multikultural keagamaan dapat disimpulkan bahwa persepsi siswa Madrasah Tsanawiyah

15 Tilaar. (2012). Kaleidoskop Pendidikan Nasional. Jakarta: Kompas Media Nusantara, hlm. 7. sangat positif dalam memandang sikap toleransi perlu dibangun dalam keberagaman bangsa Indonesia yang berbeda agama, suku, dan adat sebagai upaua mencegah praktik radikalisme secara dini sejak dari lembaga pendidikan dasar melalui pemahaman yang pendidikan multikultural dan keagamaan.

Sebagai indikator hasil penelitian dilaksanakan melalui pendekatan kualitatif-deskriptif dengan populasi sebanyak 285 siswa dan sample yang menjawab angket sebanyak 168 responden $(58,95 \%$ dari populasi 285 siswa/i). Dari sample tersebut menjawab pertanyaan dengan nilai ideal pada skala 5 sebesar 86, $74 \%$. Hal ini menunjukan bahwa persepsi siswa terhadap pendidikan multikultural keagamaan sangat positif. Hasil pengolahan data dari 30 item pernyataan yang disampaikan kepada responden itu sebagian besar menjawab positif dengan skore SANGAT BAIK (SB).

\section{DAFTAR PUSTAKA}

Kementrian Agama. (2010). Panduan Model Kurikulum Pendidikan Agama Islam Berbasis Multikultural Sekolah Dasar. Kementerian Agama Direktorat Jenderal Pendidikan Islam Direktorat Pendidikan Agama Islam Pada Sekolah. 
Al-Arifin, A. H. (2012). Implementasi Pendidikan Multikultural Dalam Praksis Pendidikan di Indonesia. Jurnal Pembangunan Pendidikan: Fondasi dan Aplikasi.

Edy. (2018). Pendidikan Multikultural dalam Perspektif Pendidikan Islam. Bogor: UIKA PRESS.

H.A. Rusdiana, S. Y. (2015). Pendidikan Multikultural: Suatu Upaya Penguatan Jati Diri Bangsa. Bandung: Pustaka Setia.

Jalaludin, A. N. (2015). Agama dan Konflik Sosial: Studi Kerukunan Umat Beragama, Radikalisme dan Konflik Antarumat Beragama. Bandung: CV Pustaka Setia.

Mubarok, H. (2010). Memahami Kembali Arti Keragaman: Dimensi Eksistensial, Sosial dan Institusional". Harmoni. Jurnal Multicultural \& Multireligius. IX (35) : 23-34.

Mubit, R. (2016). Peran Agama Dalam Multikulturalisme Masyarakat Indonesia". Jurnal Episteme. Jurnal Pengembangan ilmu Keislaman IAIN Tulungagung. 11 (01) : 56-72.

Mujiburrahman. (2013). Islam Multikultural: Hikmah, Tujuan, dan Keanekaragaman alam Islam. Jurnal Addin. 7 (01).
Nata, A. (2005). Pendidikan Islam di Era Global: Pendidikan Mujltikultural, Pendidikan Multi Iman, Pendidikan Agama, Moral dan Etika. Jakarta: UIN Jakarta Press.

Rosyadi, A. R. (2017). Pendidikan Islam dalam Perspektif Kebijakan pendidikan Nasional. Bogor: UIKA PRESS.

Sudrajat. (2014). Revitalisasi Pendidikan Multikultural dalam Pembelajaran. Jurnal Pembangunan Pendidikan: Fondasi dan Aplikasi. 2 (01): 121.

Suparta, M. (2008). Islamic Multicultural Education: Sebuah Refleksi atas Pendidikan agama Islam di Indonesia. Jakarta: al-Ghazali Center.

Suyatno. (2013). Multikulturalisme Dalam Sistem Pendidikan Agama Islam: Problematika Pendidikan Agama Islam di Sekolah. Jurnal Addin. 7 (01) : 47-61.

Tilaar, H. (2012). Kaleidoskop Pendidikan Nasional. Jakarta: Kompas Media Nusantara. 